\title{
Abundance estimates of killer whales at subantarctic Marion Island
}

\author{
Ryan R. Reisinger*, P. J. Nico de Bruyn, Marthán N. Bester \\ Mammal Research Institute, Department of Zoology and Entomology, University of Pretoria, Private Bag X20, Hatfield 0028, \\ South Africa
}

\begin{abstract}
Killer whales Orcinus orca are apex predators known to have important effects on marine ecosystems. A fundamental step towards understanding their role in ecosystems, and vital for their informed management and conservation, is the rigorous estimation of their abundance. Studies concerning this species have used mark-recapture analytical techniques to estimate abundance, but enumeration of identifiable individuals is more common. This study estimated the abundance of killer whales occurring inshore at subantarctic Marion Island. Mark-recapture analyses were performed using nearly 10000 photographs taken from 2006 to 2009. Using careful quality control criteria, we identified 37 ind. The evident capture heterogeneity violates the underlying assumptions of the open population POPAN parameterization in the software program MARK we initially used. We thus used the simpler Chapman modified Lincoln-Petersen estimator, calculating a population size of 37 ind. (95\% CI = 29 to 44) for the period 2006 to 2007 and 32 ind. (95\% CI = 30 to 33) for 2007 to 2008. Both estimates are close to the catalogue size, suggesting that enumeration is an accurate measure of abundance in this study. Our results are comparable to recent abundance estimates for the neighbouring Crozet Archipelago ( 1000 km due east). No rigorous approach has been used previously to estimate the abundance of killer whales at Marion Island. This estimate provides a foundation for further research related to the sociality and potential ecological impact of this population of killer whales in the Southern Ocean.
\end{abstract}

KEY WORDS: Orcinus orca $\cdot$ Photo-identification $\cdot$ Population size $\cdot$ Mark-recapture $\cdot$ Southern Ocean · Count Resale or republication not permitted without written consent of the publisher

\section{INTRODUCTION}

Killer whales, Orcinus orca, are cosmopolitan (Heyning \& Dahlheim 1988) apex predators with different populations preying on a variety of taxa including cephalopods, bony and cartilaginous fishes, reptiles, birds and mammals (Hoyt 1990, Jefferson et al. 1991, Ford 2009). As apex predators they potentially have important effects on marine ecosystems (e.g. Estes et al. 1998, Williams et al. 2004) and the diversity of their prey means they can influence ecosystems at various levels and intensities (e.g. Springer et al. 2003, Ford \& Ellis 2006). In the Southern Ocean, southern elephant seals, Mirounga leonina, underwent a population decline between the 1950s and 1990s throughout most of their breeding range (McMahon et al. 2005) and killer whale predation has been suggested as one of the causes of this decline at 2 breeding locations: Marion Island (Condy et al. 1978) and the Crozet Archipelago (Guinet et al. 1992).

A critical step towards understanding the role of killer whales in ecosystems, however, and necessary for quantitatively evaluating the effects of killer whales in ecosystems, is the estimation of their abundance. Moreover, abundance estimates are vital for the informed management and conservation of cetaceans (e.g. Karczmarski et al. 1999, Keith et al. 2002, Parra et al. 2006) and trends in the abundance of marine top predators may be useful in detecting environmental changes in marine ecosystems (Weimerskirch et al. 2003, Boyd et al. 2006).

Forney \& Wade (2007) reviewed worldwide killer whale abundance, estimating a minimum global population size of 50000 , but abundance data are poor for 
many regions and the authors identified the need for further estimates. Regional abundance estimates for the Southern Ocean, based on line-transect surveys, indicate that killer whales are relatively common in these waters. Hammond (1984) estimated 38278 (CV = $0.63)$ killer whales in the Indian Ocean sector of the Southern Ocean, Kasamatsu \& Joyce (1995) estimated $80400(\mathrm{CV}=0.15)$ individuals in the Southern Ocean with uncorrected abundance estimates for the Indian Ocean sector totalling 12093 ( $\mathrm{CV}=0.44$ to 0.96$)$, and most recently Branch \& Butterworth (2001) estimated $24790(\mathrm{CV}=0.23)$ killer whales south of $60^{\circ} \mathrm{S}$.

In the southern Indian Ocean, rigorous local population size estimates are only available for Possession Island (Crozet Archipelago). Poncelet et al. (2010) used mark-recapture (MR) methodology to estimate the population size at 98 animals between 1988 and 1989 (95\% CI $=70$ to 156) and 37 ind. between 1998 and $2000(95 \% \mathrm{CI}=32$ to 62$)$. Their analyses show a worrying decline in population size and survival rates, which the authors speculate is due to changes in prey availability (southern elephant seals and large whales) and lethal interactions with illegal fisheries targeting the Patagonian toothfish Dissostichus eleginoides (see also Tixier et al. 2010). At Marion Island, no rigorous population size estimates have been produced. Keith et al. (2001) identified 26 individual killer whales from 159 photographs taken opportunistically from 1975 to 1989 and, based on simultaneous island-wide observations on a single day, Pistorius et al. (2002) approximated the population size at 25 to 30 individuals.

MR analyses of photographic identification data have been used to estimate population size in killer whales (Kuningas et al. 2007, Williams \& Thomas 2009, Poncelet et al. 2010, Durban et al. 2010) but this approach has generally been necessitated by logistical (e.g. large populations where individuals are encountered infrequently, or large and/or remote areas) or financial constraints (see Williams \& Thomas 2009, Durban et al. 2010). More commonly, the abundance of small, wellstudied killer whale populations is determined by a count of known individuals (e.g. Dahlheim et al. 1997, Matkin et al. 1999, Ford et al. 2000).

We aim to provide information required for the assessment of the ecological role of killer whales at Marion Island, and to furnish baseline information for their management and conservation there and in the broader southern Indian Ocean. Using photographic identification data collected from 2006 to 2009, we established an identification catalogue of individuals at Marion Island and used MR analyses, as well as 2 simpler methods (proportion of identifiable individuals and enumeration), to estimate the abundance of killer whales.

\section{MATERIALS AND METHODS}

Study area. Subantarctic Marion Island $\left(46^{\circ} 54^{\prime} \mathrm{S}\right.$, $37^{\circ} 45^{\prime} \mathrm{E}_{\text {; }}$ Fig. 1) is the larger $\left(296 \mathrm{~km}^{2}\right)$ of a pair of islands comprising the Prince Edward Islands group. It is situated in the southern Indian Ocean with the nearest landmass being the Crozet Archipelago, approximately $1000 \mathrm{~km}$ to the east at a similar latitude. The interplay between the Antarctic Circumpolar Current and the prominent bottom topography of the Southwest Indian Ridge results in productive turbulent water masses around the Prince Edward Islands (Ansorge \& Lutjeharms 2005), sustaining the large breeding populations of seals and seabirds.

Field methods. Land-based sightings of killer whales at Marion Island were recorded from April 2006 to April 2009. Small-vessel-based surveys are impossible because of logistic and safety concerns regarding the isolation of Marion Island and the very poor weather and sea conditions (Prince Edward Islands Management Plan Working Group 1996). Sightings were of 2 types: (1) opportunistic observations, which were recorded

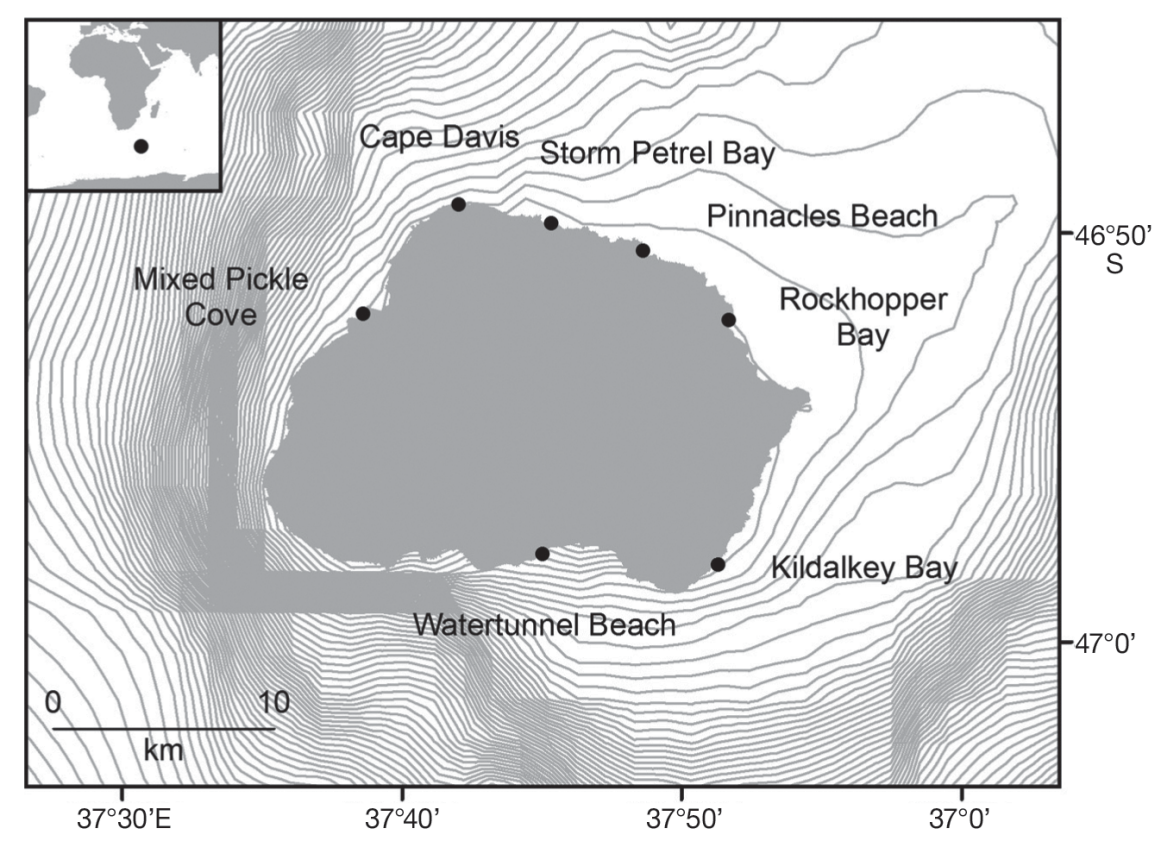

Fig. 1. Marion Island, showing killer whale observation points at the Island and approximate $50 \mathrm{~m}$ isobaths. The inset shows Marion Island's location in relation to Africa and Antarctica 
Table 1. Hours of observation effort (parentheses: no. of observation sessions) monthly at various sites on Marion Island (see Fig. 1 for locations). Long $(10 \mathrm{~h})$ sessions were performed at all sites; short (2 to $3 \mathrm{~h}$ ) sessions were performed only at Rockhopper Bay, and are presented separately from the long sessions. Dashes: no observations made

\begin{tabular}{|c|c|c|c|c|c|c|c|c|c|c|c|c|c|}
\hline \multirow[t]{2}{*}{ Site } & \multirow[b]{2}{*}{ May } & \multirow[b]{2}{*}{ Jun } & \multirow[b]{2}{*}{ Jul } & \multirow{2}{*}{$\begin{array}{l}20 \\
\text { Aug }\end{array}$} & \multirow{2}{*}{ Sep } & \multirow[b]{2}{*}{ Oct } & \multirow[b]{2}{*}{ Nov } & \multirow[b]{2}{*}{ Dec } & \multirow[b]{2}{*}{ Jan } & \multicolumn{2}{|c|}{-2009} & \multirow[b]{2}{*}{ Apr } & \multirow[t]{2}{*}{ Total } \\
\hline & & & & & & & & & & Feb & Mar & & \\
\hline Mixed Pickle Cove & - & - & - & - & - & - & - & - & $10(1)$ & $10(1)$ & - & - & $20(2)$ \\
\hline Cape Davis & - & - & - & - & - & $10(1)$ & - & - & - & $10(1)$ & $10(1)$ & - & $30(3)$ \\
\hline Storm Petrel Bay & - & - & - & $10(1)$ & $10(1)$ & $20(2)$ & $20(2)$ & - & - & $10(1)$ & - & - & $70(7)$ \\
\hline Pinnacles Beach & - & - & - & $10(1)$ & $10(1)$ & $20(2)$ & $10(1)$ & $20(2)$ & - & - & - & - & $70(7)$ \\
\hline Rockhopper Bay & - & - & - & - & - & - & $10(1)$ & $20(2)$ & - & - & - & - & $30(3)$ \\
\hline Kildalkey Bay & - & - & - & $10(1)$ & $20(2)$ & $20(2)$ & $30(3)$ & $20(2)$ & - & $10(1)$ & $10(1)$ & - & $120(12)$ \\
\hline Watertunnel Beach & - & - & - & $10(1)$ & $30(3)$ & $20(2)$ & $30(3)$ & $10(1)$ & - & $20(2)$ & - & - & $120(12)$ \\
\hline All sites (long sessions) & - & - & - & $40(4)$ & $70(7)$ & $90(9)$ & $100(10)$ & 70 & $10(1)$ & $60(6)$ & $20(2)$ & - & $460(46)$ \\
\hline $\begin{array}{r}\text { Rockhopper Bay } \\
\text { (short sessions) }\end{array}$ & $14(7)$ & $25(12)$ & $24(12)$ & $24(8)$ & $27(9)$ & $18(6)$ & $21(7)$ & $24(8)$ & $24(8)$ & $15(5)$ & $27(9)$ & $6(2)$ & $249(93)$ \\
\hline
\end{tabular}

from April 2006 to April 2009 while observers were engaged in various field activities, mostly systematic pinniped monitoring (see de Bruyn et al. 2008 for further pinniped monitoring details); and (2) dedicated observation sessions, which were conducted at various points on the north, east and south coasts of the island (Fig. 1) from May 2008 to April 2009 (Table 1). We consider these locations a representative inshore sampling/ survey area as killer whales mainly patrol beaches along the eastern half of the island (Keith et al. 2001, Pistorius et al. 2002). During these sessions, a trained observer would remain at a point and visually search for killer whales for a predetermined length of time. Such dedicated observation sessions were either short or long. Short ( 2 to $3 \mathrm{~h}$ ) observation sessions were performed 93 times at Rockhopper Bay (Fig. 1), totalling 249 h (Table 1). Sessions were performed at regular intervals throughout each month (approximately every $3 \mathrm{~d}$ ), starting at the same time (approximately 11:00 or 14:00 h). Long (10 h uninterrupted) observation sessions were performed 46 times at 8 locations from August 2008 to March 2009, totalling 460 h (Table 1). Sessions were conducted on a weekly cycle.

For all types of observation, the location, group size and age and/or sex class composition of the group, as well as direction of movement, were recorded for each sighting. Distance from shore was recorded following Condy et al. (1978), where Zone 1 is within $5 \mathrm{~m}$ of shore; Zone 2 is 5 to $100 \mathrm{~m}$ from shore, usually extending to the first kelp (Macrocystis sp.) belt; Zone 3 is 100 to $500 \mathrm{~m}$ from shore, usually extending to the second kelp belt; and Zone 4 is beyond $500 \mathrm{~m}$ from shore. As many individuals as possible were photographed using an 8 megapixel Canon 350D with a Canon 75-200 mm f4.5-5.6 lens, or a 10.2 megapixel Nikon D200 with either a Nikon $80-200 \mathrm{~mm}$ f2.8 lens or a Nikon 80$400 \mathrm{~mm}$ f4.5-5.6 lens. To minimize capture hetero- geneity, observers made a conscious effort to direct equal photographic effort at all individuals, independent of any noticeable marks on the individuals. Observers continued to take photographs as long as a group was within photographic range, irrespective of whether all individuals were photographed.

Treatment of photographs. Photographs were carefully examined and assigned a quality $(Q)$ score from 1 (unusable for MR analyses) to 5 (excellent), independent of the distinctiveness of the individual represented. The $Q$ score took into account the size of the dorsal fin in the photograph, focus, lighting, exposure, the angle of the dorsal fin to the photographer and the proportion of the dorsal fin obscured by water. Photographs of $Q 4$ and Q5 were well exposed and well lit, in focus and the dorsal fin was sufficiently large in the photograph, relatively perpendicular to the photographer and not obscured by water. Although photographs of $Q 1$ to $Q 5$ were considered for the catalogue of identifiable individuals, only photographs of Q4 to Q5 were considered for MR analyses (Friday et al. 2000).

Individuals were identified based on natural markings of the dorsal fin and saddle patch (Bigg et al. 1987), mainly the pattern of nicks, notches and mutilations along the trailing edge of the dorsal fin. Individuals that were considered recognizable were assigned a unique numeric identifier, and included in a catalogue with which all subsequent photographs were compared (see Tosh et al. 2008). Both left and right side images of dorsal fins were used, as they could reliably be matched to the same individual. Catalogued individuals were not rated according to their distinctiveness, rather all catalogued individuals were considered reliably identifiable from photographs of Q4 to Q5, other than calves, which were excluded from MR analyses.

For all photographs of $Q 4$ and Q5, a ratio was calculated relating the number of dorsal fins that could be 
reliably identified (excluding calves) to the total number of photographed fins. This calculation was performed for each sighting, and subsequently an overall ratio was calculated representing the proportion of identifiable individuals $(\theta)$.

Analyses. MR analyses of the sighting histories of recognizable individuals were firstly performed using the software program MARK (White \& Burnham 1999). Persighting captures were pooled into monthly capture events, thus a single calendar month constituted a sampling occasion. Population parameters were estimated using the open-population POPAN parameterization (Schwarz \& Arnason 1996, 2009) The initial analysis is based on the fully time-dependent Cormack-Jolly-Seber (CJS) model $\left(\Phi_{t} p_{t} b_{t}\right.$, where $\Phi$ is survival, $p$ is probability of capture, $b$ is probability of entry) and the first step in the analysis involves goodness-of-fit (GOF) tests for the CJS model using the program RELEASE GOF to validate model assumptions. Models were constructed for combinations of time-dependence $(t)$ and consistency $(\cdot)$ for $\Phi$ and $p$, and seasonal ( $s$ ) variation was allowed for $p$. Based on the seasonal abundance of killer whales at Marion Island (Reisinger et al. 2011), September to December of each year was considered 'peak' occurrence whereas January to August was considered 'low' abundance. The most appropriate model was selected using the smallsample corrected Akaike's information criterion ( AIC $_{\mathrm{c} i}$ Burnham \& Anderson 1998). Based on the GOF results of TEST 2 + TEST 3 in program RELEASE, a post hoc variance inflation factor $(\hat{c})$ may be estimated to adjust for extra-binomial variation in the data, resulting in a quasi$\mathrm{AIC}_{\mathrm{C}}\left(\mathrm{QAIC} \mathrm{C}_{\mathrm{C}}\right)$. Median and bootstrap GOF are not available in the POPAN parameterization.

Because of sparse data, overparameterization and possible violation of one of the assumptions underlying the POPAN approach (see 'Results' and 'Discussion'), we also calculated abundance using the Chapman-modified Lincoln-Petersen 2-occasion estimator (Chapman 1951). Captures in September to December (the months of peak killer whale occurrence at Marion Island; Reisinger et al. 2011) were pooled into a single capture occasion for each year (2006, 2007 and 2008) and abundance was estimated for 2006 to 2007 and 2007 to 2008. Pooling captures from the peak occurrence months min- imized the effects of temporary immigration and emigration on this closed population model.

Finally, we calculated abundance simply as the number of non-calf individuals determined from photographs of Q4 to Q5 during the study period, divided by the proportion of identifiable individuals $(\theta)$.

The MR abundance estimates apply only to the population of marked animals (excluding calves) and these estimates were expanded to include the entire population (including calves) by dividing $N$ (the MR population size estimate) by $\theta$, yielding total abundance $\left(N_{\text {total }}\right)$. Variance was estimated using the delta method as:

$$
\operatorname{var}\left(N_{\text {total }}\right)=N_{\text {total }}^{2}\left(\frac{\operatorname{var}(N)}{N^{2}}+\frac{1-\theta}{n \theta}\right)
$$

where $n$ is the total number of dorsal fins from which $\theta$ was calculated. Confidence intervals for $N_{\text {total }}$ assumed the same error distribution as the MR estimates (Wilson et al. 1999).

\section{RESULTS}

From April 2006 to April 2009 (inclusive), killer whales were sighted 846 times at Marion Island and 9724 photographs were taken. Table 2 shows the number of sightings per year, the number of photographs taken in various categories and the number of photographic identifications in various categories. Killer whales were regularly observed close inshore; $50 \%$ of sightings included sightings in Zone 1 and $65 \%$ included sightings in Zones 1 \& 2. Group size ranged from 1 to 13 ind. (Fig. 2) and the proportion of individuals photographed in each group per occasion ranged from 0 to $100 \%$. In total, 37 ind. were identified, of which 7 were classified as adult males, 22 as adult females, 5 as unknown age-sex class and 3 as calves (born during the study period and identified by their colouration, relative size, close association with an adult female and previous absence from groups). Left and right side dorsal fin images were available for 30 ind.; the remaining 7 were photographed from one side only. Only 30 ind. were included in the POPAN MR analyses, the remaining 7 were calves (3 ind.) or

Table 2. Sightings of killer whales at Marion Island, photographic effort, number of identifications and individuals identified, April 2006 to April 2009. Q1-Q5: see 'Treatment of photographs' in 'Materials and methods'

\begin{tabular}{|lcccccccc|}
\hline \multirow{2}{*}{ Period } & \multicolumn{2}{c}{ Sightings } & \multicolumn{2}{c}{ Photographs } & \multicolumn{2}{c|}{ Identifications } & Unique individuals & New individuals \\
& All & Photographic & Q1-Q5 & Q4-Q5 & Q1-Q5 & Q4-Q5 & sighted & identified \\
\hline $2006-2007$ & 239 & 83 & 334 & 49 & 190 & 37 & 21 & 21 \\
$2007-2008$ & 166 & 94 & 1334 & 86 & 299 & 54 & 21 & 6 \\
$2008-2009$ & 441 & 209 & 8056 & 1446 & 4075 & 1283 & 30 & 37 \\
$2006-2009$ & 846 & 386 & 9724 & 1581 & 4564 & 1374 & 37 \\
\hline
\end{tabular}




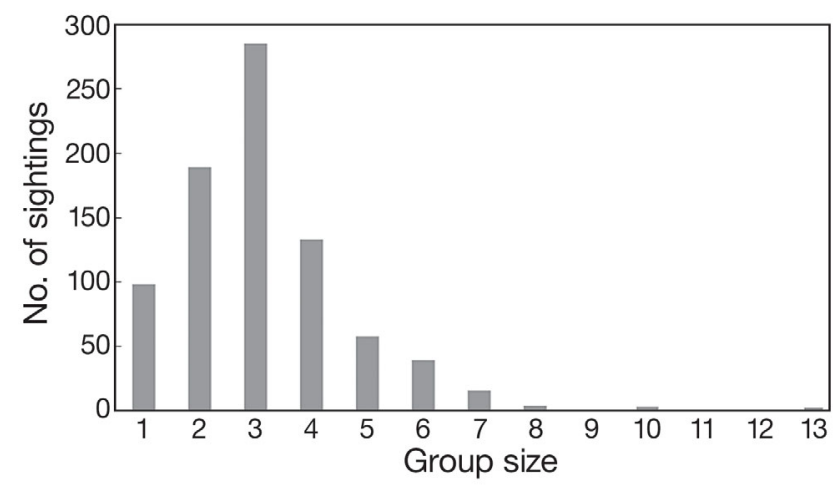

Fig. 2. Frequency distribution of group sizes of killer whales sighted at Marion Island, April 2006 to April 2009

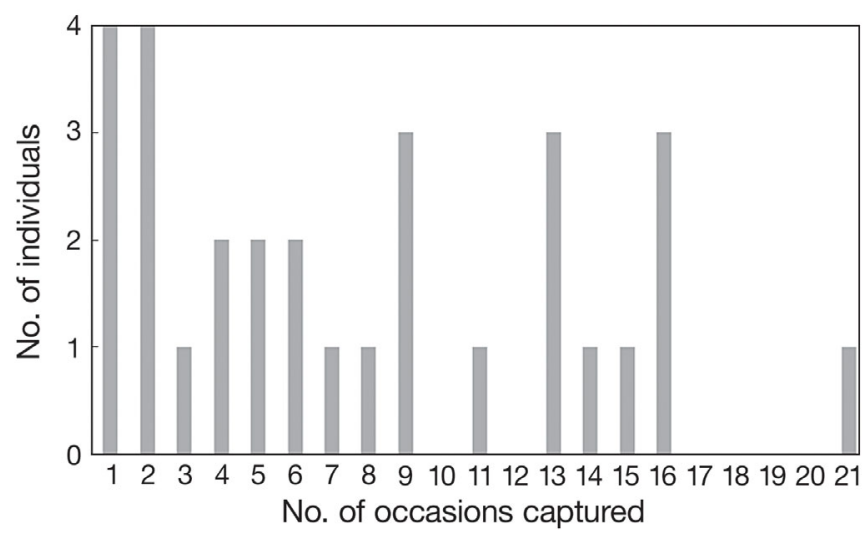

Fig. 3. Sighting frequency distribution of identifiable killer whales at Marion Island from April 2006 to April 2009 (photographs of $Q 4$ to $Q 5$ only - see 'Treatment of photographs' in 'Materials and methods'; calves excluded)

were not identified in photos of Q4-Q5 (4 ind.). Fig. 3 shows the sighting frequency distribution of these animals and Fig. 4 shows the discovery curve, or the cumulative number of identified individuals (both figures used $Q 4$ to $Q 5$ only and calves were excluded). Only 27 ind. were included in the Chapman MR analyses; of the 10 excluded individuals, 3 were calves and 7 were not identified in photos of $Q 4$ to $Q 5$ in the sampling occasions (September-December of each year).

Of the 6 biologically sensible model combinations tested in the POPAN approach, one did not reach numerical convergence. Parameters for each occasion were often inestimable because of sparse data. Although the result of TEST $2+$ TEST 3 in program RELEASE GOF ( $=1.30$; Table 3 ) indicated only slight overdispersion in the data (Cooch \& White 2009), program RELEASE reported insufficient data to perform tests for a number of occasions and TEST 2 was rejected. The most parsimonious model according to the $\mathrm{QAIC}_{\mathrm{c}}$ scores was $\Phi . p_{s} b_{t}$ (constant survival, probabil-

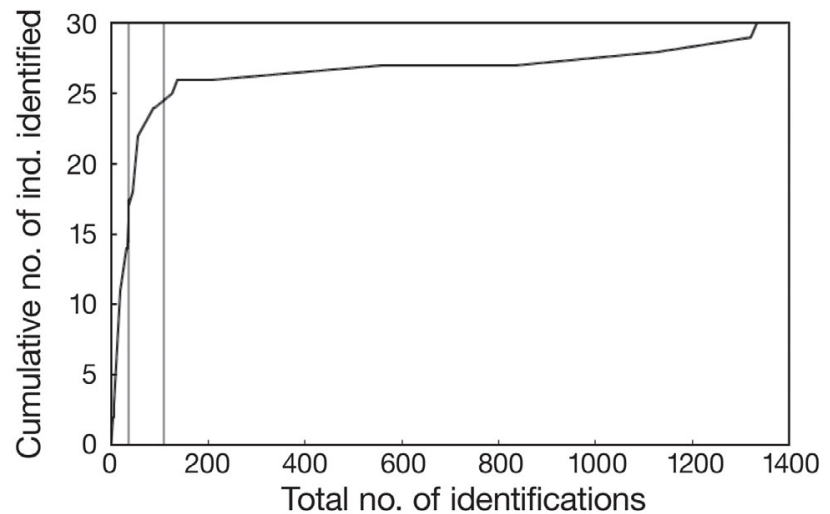

Fig. 4. Discovery curve, or cumulative number of individuals identified, for killer whales at Marion Island, April 2006 to April 2009 (photographs of Q4 to Q5 only, calves excluded). Vertical lines indicate the period including study years (2006-2007, 2007-2008 and 2008-2009)

Table 3. Program RELEASE goodness-of-fit results for the fully time-dependent Cormack-Jolly-Seber model tested in a markrecapture analysis of individual sighting histories of killer whales at Marion Island, April 2006 to April 2009, using the open-population POPAN parameterization in program MARK. $\hat{c}$ : post hoc variance inflation factor. TEST 2 + TEST 3 is the overall test statistic; TEST 2 tests for equal capture probability and TEST 3 tests for equal survival. SR tests whether survival is dependent on whether or not an individual was seen previously and SM tests if when an individual is seen again is dependent on whether or not the individual was seen previously (Cooch \& White 2009)

\begin{tabular}{|lcrrr|}
\hline Test & $\hat{c}$ & $\chi^{2}$ & df & $\mathrm{p}$ \\
\hline TEST 2 + TEST 3 & 1.30 & 41.58 & 32 & 0.12 \\
TEST 2 & 2.11 & 40.12 & 19 & 0.00 \\
TEST 3 & 0.11 & 1.46 & 13 & 1.00 \\
TEST 3.SR & 0.08 & 0.53 & 7 & 1.00 \\
TEST 3.SM & 0.17 & 0.94 & 6 & 0.99 \\
\hline
\end{tabular}

ity of capture varies seasonally and probability of entry varies with capture occasion), and this model estimated population size at 33 ind. $(\mathrm{SE}=2.91,95 \% \mathrm{CI}=$ 27 to 38). No models had a $\triangle \mathrm{QAIC}_{\mathrm{c}}$ (difference between the $\mathrm{QAIC}_{\mathrm{c}}$ of the model in question and that of the top-ranked model) of $<2$ units, which would have indicated that they were also likely descriptors of the data (Burnham \& Anderson 1998). The proportion of identifiable individuals was $0.77(\mathrm{SE}=0.34)$ and, based on model $\Phi . p_{s} b_{t}$, total abundance was estimated at 42 ind. ( $\mathrm{SE}=3.83,95 \% \mathrm{CI}=35$ to 50 ).

The Chapman-modified Lincoln-Petersen estimator yielded total population sizes of 37 and 32 ind. in 2006 to 2007 and 2007 to 2008, respectively (Table 4), and the simple abundance estimate (number of individuals identified from photographs of $Q 4$ to $Q 5$, excluding calves, divided by $\theta$ ) yielded 39 ind. 
Table 4. Chapman-modified Lincoln-Petersen estimates of the abundance of killer whales at Marion Island

\begin{tabular}{|lccccccc|}
\hline \multirow{2}{*}{ Period } & \multicolumn{3}{c}{ Marked population } & \multicolumn{3}{c|}{ Total population } \\
& $N$ & SE & $95 \%$ CI & N & SE & $95 \%$ CI \\
\hline $2006-2007$ & 29 & 4.72 & $23-35$ & 37 & 6.15 & $29-44$ \\
$2007-2008$ & 25 & 0.87 & $23-26$ & 32 & 1.21 & $30-33$ \\
& & & & & & \\
\hline
\end{tabular}

\section{DISCUSSION}

The observed group sizes (Fig. 2) of killer whales at Marion Island are consistent with earlier observations for the island (Condy et al. 1978, Keith et al. 2001, Tosh et al. 2008), as well as for populations of pinnipedeating killer whales elsewhere, likely an optimal group size for maximizing energy intake in such populations (Baird \& Dill 1996). The most frequent group size observed ( 3 ind.) is comparable to average group sizes of 4.2 (Condy et al. 1978), 3.6 (Keith et al. 2001) and 3.4 (Tosh et al. 2008) reported previously at Marion Island, 3.2 (modal group size of 2) at Punta Norte (Lopez \& Lopez 1985) and a modal group size of 3 at Vancouver Island, British Columbia (Baird \& Dill 1996). The largest groups observed at Marion Island included identified individuals that were mostly observed separately on other occasions (Tosh et al. 2008, P.J.N.d.B. unpublished data), indicating that large groups formed temporarily during interactions of smaller groups, likely for socializing and perhaps cooperative hunting (Baird \& Dill 1996). This illustrates that, albeit for killer whales in different habitats and aquatic ecosystems, a stable group size aligned with the energetic constraints of predation on marine mammals has evolved (e.g. Baird \& Dill 1996).

The number of individuals identified in the present study is substantially larger than that identified by Keith et al. (2001) but the proportion of adult females in the current catalogue $(59 \%)$ is almost identical to that in Keith et al.'s study (58\%), although the proportion of adult males differs markedly (19\% in the present study compared with $35 \%$ ). The opportunistic nature of Keith et al.'s (2001) study may have meant that males were more likely to be observed because of their much larger dorsal fins, potentially explaining the higher proportion of males in that study. The number of individuals identified here is similar to photographic identification studies at Punta Norte (30 ind. in 1975 to 1997; Iñíguez 2001) and Possession Island (32 ind. in 1998 to 2000; Poncelet et al. 2010). The sighting frequency distribution (Fig. 3) suggests a population of regularly occurring animals; only 4 ind. were seen during one month only and the majority of animals were seen in a number of months during the study period. The presence of a large proportion of transient (not to be confused with the eastern North Pacific killer whale ecotype) or migratory animals is therefore unlikely. Further, there is no suggestion of separate populations of transient/migratory and resident (again, not to be confused with the eastern North Pacific killer whale ecotype) animals, as sighting frequencies are relatively evenly distributed without clear clustering.

The discovery curve (Fig. 4) shows the expected rapid initial increase in 2006 to 2007 and 2007 to 2008 but, despite the far greater photographic effort in 2008 to 2009 (Table 2) and the larger number of sightings, it appears to level off. This asymptotic tendency in the discovery curve indicates that most individuals in the population have been identified; however, only continuation of the photographic MR effort in a structured protocol can confirm this (e.g. Wilson et al. 1999, Baker et al. 2006).

\section{Assumptions: validation and violations}

Validation of the assumptions underlying MR methods is critical in providing relatively unbiased estimates of population parameters (Begon 1983). The natural characteristics used to identify killer whales have proven to be long-lasting, allowing individuals to be recognized for years in long-term studies (e.g. Bigg et al. 1987, Bigg et al. 1990, Baird \& Whitehead 2000, Parsons et al. 2009, Ivkovich et al. 2010). This makes killer whales conducive to MR analysis following rigorous photographic surveying and we therefore considered mark loss in this study as being negligible. Sampling was instantaneous, and sampling effort was consciously similarly distributed between marked and unmarked animals, although heterogeneous capture probabilities because of differences in the behaviour of individuals are present in many photographic identification MR studies (e.g. Hammond 1986, see also Baird $\&$ Dill 1995). Any further violations of equal capture probabilities were minimized by imposing careful photographic quality criteria; however, capture heterogeneity is evident in this study. In the POPAN approach, TEST 2 (capture heterogeneity) in program RELEASE was rejected (Table 3). The most likely explanations are differences in behaviour of individuals (Hammond 1986) and slight temporary emigration.

\section{MR estimates compared with simpler methods}

Capture homogeneity is one of the key assumptions underlying the POPAN and other Jolly-Seber approaches, and violation of this assumption casts severe doubt on estimates using this method. Evidence of 
capture heterogeneity in this study thus leads us to prefer the simpler Chapman-modified Lincoln-Petersen estimator to the POPAN approach, so the 2 simplest approaches we took to estimate abundance seem most appropriate in this case.

Applying the proportion of identifiable individuals $(\theta)$ to the number of non-calf individuals identified from photos of Q4-Q5 yields a population size of 39 ind. - close to the number of individuals in the catalogue (37 ind.), the POPAN MR estimates (42, 95\% $\mathrm{CI}=35$ to 50) and the Chapman MR estimates (37, 95\% $\mathrm{CI}=29$ to 44 and $32,95 \% \mathrm{CI}=30$ to 33 ). This agreement, combined with the sighting frequency pattern (Fig. 3) and the asymptotic tendency of the discovery curve (Fig. 4), indicates that most of the identifiable proportion of the population has been included in the catalogue, and lends confidence to the catalogue size (complete enumeration over time) as a rigorous abundance estimate free of the assumptions underlying MR estimates. Although the catalogue may also be subject to some bias, it is more precise than MR estimates. Our estimate is based on only $3 \mathrm{yr}$ of data, and continued study is undoubtedly required and may resolve problems with the MR analyses. The thorough establishment of a photographic identification catalogue and the continuation of the photographic identification study will be of future use to investigate various questions related to population parameters, social ecology and movement of individuals.

\section{Comparison with other studies and defining the 'population'}

Our catalogue size should not be compared with that of Keith et al. (2001) with a view to identify abundance trends, because of the highly opportunistic nature of that study. In broad terms, our population size estimates are similar to the most recent estimate at Possession Island (37 ind., 95\% CI $=32-62$; Poncelet et al. 2010). Although the Possession Island population has undergone a marked decline, no comparable data are available for Marion Island. The birth of at least 3 calves at Marion Island during 2008 to 2009 suggests a higher fecundity than that reported at Possession (Guinet \& Bouvier 1995).

This begs the question as to what constitutes the 'population'. In terms of the MR methodology, the 'population' refers to individuals available to be captured during the study, and thus refers to any killer whales that may occur in the inshore area. We have discussed why it is unlikely that such a population includes a large proportion of transient individuals and can broadly refer to the population in this case as those killer whales that occur, at least seasonally, inshore at
Marion Island (however, it should be noted that there may be differences among groups in the use of inshore areas; Baird \& Dill 1995). This population likely includes animals occurring at neighbouring Prince Edward Island. Prince Edward Island is only $19 \mathrm{~km}$ from Marion Island, a much smaller distance than the more than $40 \mathrm{~km}$ of coastline included in our survey area, and the only photograph available of a killer whale at Prince Edward Island (provided by R. Tarr, Oceans and Coasts, Department of Environmental Affairs, Rogge Bay, South Africa) was reliably identified as an individual included in the Marion catalogue.

Because our data are completely biased to killer whales occurring inshore, we cannot exclude the existence of a separate population of offshore animals (as exists in the eastern North Pacific; Dahlheim et al. 2008), and our abundance estimate would not apply to such a population. No studies have been conducted on the medium- and large-scale movement of killer whales at Marion Island, but inshore abundance data (Reisinger et al. 2011, see also Condy et al. 1978, Keith et al. 2001) indicate potential seasonal movement offshore or increased range, both of which may be accompanied by a potential diet switch (e.g. Mikhalev et al. 1981).

\section{Future research}

Although our abundance estimate is a novel and critical step in elucidating the role of killer whales in the Marion Island marine ecosystem-as well as being valuable for any conservation and management decisions in the region and for comparisons with other killer whale populations-the current photographic identification study should continue. Future research investigating the population structure and spatiotemporal distribution of killer whales at Marion Island can now be initiated in the context of this rigorous abundance estimate.

Acknowledgements. We thank the South African Department of Environmental Affairs for providing logistical support within the South African National Antarctic Programme and the Department of Science and Technology (administered through the National Research Foundation) for funding the marine mammal monitoring programme at Marion Island. Various overwintering and relief expedition members recorded their sightings and provided photographs. We especially thank T. Mufanadzo, C. Oosthuizen, M. Phalanndwa and C. Tosh for their excellent field efforts. Finally, the comments of anonymous reviewers greatly improved this manuscript.

\section{LITERATURE CITED}

Ansorge IJ, Lutjeharms JRE (2005) Direct observations of eddy turbulence at a ridge in the Southern Ocean. Geophys Res Lett 32:L14601 doi:10.1029/2005GL022588 
Baird RW, Dill LM (1995) Occurrence and behaviour of transient killer whales: seasonal and pod-specific variability, foraging behaviour, and prey handling. Can J Zool 73: 1300-1311

Baird RW, Dill LM (1996) Ecological and social determinants of group size in transient killer whales. Behav Ecol 7: 408-416

Baird RW, Whitehead H (2000) Social organization of mammal-eating killer whales: group stability and dispersal patterns. Can J Zool 78:2096-2105

Baker JD, Harting AL, Johanos TC (2006) Use of discovery curves to assess abundance of Hawaiian monk seals. Mar Mamm Sci 22:847-861

Begon M (1983) Abuses of mathematical techniques in ecology: application of Jolly's capture-recapture method. Oikos 40:155-158

Bigg MA, Ellis GM, Ford JKB, Balcomb KC (1987) Killer whales: a study of their identification, genealogy, and natural history in British Columbia and Washington State. Phantom Press and Publishers, Nanaimo, BC, Canada

Bigg MA, Olesiuk PF, Ellis GM, Ford JKB, Balcomb KC (1990) Social organization and genealogy of resident killer whales (Orcinus orca) in the coastal waters of British Columbia and Washington State. Rep Int Whal Comm Spec Issue 12:383-405

Boyd IL, Wanless S, Camphuysen C (2006) Top predators in marine ecosystems: their role in monitoring and management. Cambridge University Press, Cambridge

Branch TA, Butterworth DS (2001) Estimates of abundance south of 60 degrees $\mathrm{S}$ for cetacean species sighted frequently on the $1978 / 79$ to $1997 / 98$ IWC/IDCR-SOWER sighting surveys. J Cetacean Res Manag 3:251-270

Burnham KP, Anderson DR (1998) Model selection and inference: a practical information-theoretic approach. SpringerVerlag, New York

Chapman DH (1951) Some properties of the hypergeometric distribution with applications to zoological censuses. Univ Calif Publ Stat 1:131-160

- Condy PR, van Aarde RJ, Bester MN (1978) The seasonal occurrence and behaviour of killer whales Orcinus orca, at Marion Island. J Zool 184:449-464

Cooch E, White G (eds) (2009) Program MARK: a gentle introduction, 8th edn. Available at www.phidot.org/software/ mark/docs/book/

Dahlheim ME, Ellifrit DK, Swenson JD (1997) Killer whales of southeast Alaska: a catalogue of photo-identified individuals. Day Moon Press, Seattle, WA

> Dahlheim ME, Schulman-Janiger A, Black N, Ternullo R, Ellifrit DK, Balcomb KC (2008) Eastern temperate North Pacific offshore killer whales (Orcinus orca): occurrence, movements, and insights into feeding ecology. Mar Mamm Sci 24:719-729

de Bruyn PJN, Tosh CA, Oosthuizen WC, Phalanndwa MV, Bester MN (2008) Temporary marking of unweaned southern elephant seal (Mirounga leonina L.) pups. S Afr J Wildl Res 38:133-137

> Durban J, Ellifrit D, Dahlheim M, Waite J and others (2010) Photographic mark-recapture analysis of clustered mammal-eating killer whales around the Aleutian Islands and Gulf of Alaska. Mar Biol 157:1591-1604

Estes JA, Tinker MT, Williams TM, Doak DF (1998) Killer whale predation on sea otters linking oceanic and nearshore ecosystems. Science 282:473-476

Ford JKB (2009) Killer whale Orcinus orca. In: Perrin WF, Würsig B, Thewissen JGM (eds) Encyclopedia of marine mammals, 2nd edn. Academic Press, San Diego, CA, p 650-657
Ford JKB, Ellis GM (2006) Selective foraging by fish-eating killer whales Orcinus orca in British Columbia. Mar Ecol Prog Ser 316:185-199

Ford JKB, Ellis GM, Balcomb KC III (2000) Killer whales: the natural history and genealogy of Orcinus orca in the waters of British Columbia and Washington. University of British Columbia Press, Vancouver, BC

Forney KA, Wade P (2007) Worldwide distribution and abundance of killer whales. In: Estes JA, Brownell RL, DeMaster DP, Doak DF, Williams TM (eds) Whales, whaling and ocean ecosystems. University of California Press, Berkeley, CA, p 145-162

> Friday N, Smith TD, Stevick PT, Allen J (2000) Measurement of photographic quality and individual distinctiveness for the photographic identification of humpback whales, Megaptera novaeangliae. Mar Mamm Sci 16:355-374

Guinet C, Bouvier J (1995) Development of intentional stranding hunting techniques in killer whale (Orcinus orca) calves at Crozet Archipelago. Can J Zool 73:27-33

> Guinet C, Jouventin P, Weimerskirch H (1992) Population changes, movements of southern elephant seals on Crozet and Kerguelen Archipelagos in the last decades. Polar Biol 12:349-356

Hammond PS (1984) Abundance of killer whales in Antarctic Areas II, III, IV, and V. Rep Int Whaling Comm 34:543-548

Hammond PS (1986) Estimating the size of naturally marked whale populations using capture-recapture techniques. Rep Int Whal Comm Spec Issue 8:253-282

> Heyning JE, Dahlheim ME (1988) Orcinus orca. Mamm Species 304:1-9

Hoyt E (1990) Orca, the whale called killer, 3rd edn. Camden House, Camden East, Canada

Iñíguez MA (2001) Seasonal distribution of killer whales (Orcinus orca) in Northern Patagonia, Argentina. Aquat Mamm 27:154-161

Ivkovich T, Filatova OA, Burdin AM, Sato H, Hoyt E (2010) The social organization of resident-type killer whales (Orcinus orca) in Avacha Gulf, Northwest Pacific, as revealed through association patterns and acoustic similarity. Mamm Biol 75:198-210

> Jefferson TA, Stacey PJ, Baird RW (1991) A review of killer whale interactions with other marine mammals: predation to co-existence. Mammal Rev 21:151-180

Karczmarski L, Winter PED, Cockcroft VG, McLachlan A (1999) Population analyses of Indo-Pacific humpback dolphins Sousa chinensis in Algoa Bay, Eastern Cape, South Africa. Mar Mamm Sci 15:1115-1123

Kasamatsu F, Joyce GG (1995) Current status of Odontocetes in the Antarctic. Antarct Sci 7:365-379

Keith M, Bester MN, Bartlett PA, Baker D (2001) Killer whales (Orcinus orca) at Marion Island, Southern Ocean. Afr Zool 36:163-175

Keith M, Peddemors VM, Bester MN, Ferguson JWH (2002) Population characteristics of Indo-Pacific humpback dolphins at Richards Bay, South Africa: implications for incidental capture in shark nets. S Afr J Wildl Res 32:153-162

Kuningas SM, Similä T, Hammond PS (2007) Population dynamics of killer whales (Orcinus orca) off northern Norway. Paper SC/59/SM13 presented to the International Whaling Commission Scientific Committee, June 2007, International Whaling Commission, Cambridge

Lopez JC, Lopez D (1985) Killer whales (Orcinus orca) of Patagonia, and their behavior of intentional stranding while hunting nearshore. J Mammal 66:181-183

Matkin CO, Ellis GM, Saulitis EL, Barrett-Lennard LG, Matkin DR (1999) Killer whales of southern Alaska. North Gulf Oceanic Society, Homer, AK 
McMahon CR, Bester MN, Burton HR, Hindell MA, Bradshaw CJA (2005) Population status, trends and a re-examination of the hypotheses explaining the recent declines of the southern elephant seal Mirounga leonina. Mammal Rev 35: 82-100

Mikhalev YA, Ivashin MV, Savusin VP, Zelenaya FE (1981) The distribution and biology of killer whales in the Southern Hemisphere. Rep Int Whaling Comm 31:551-566

Parra GJ, Corkeron PJ, Marsh H (2006) Population sizes, site fidelity and residence patterns of Australian snubfin and Indo-Pacific humpback dolphins: implications for conservation. Biol Conserv 129:167-180

Parsons KM, Balcomb KC, Ford JKB, Durban JW (2009) The social dynamics of southern resident killer whales and conservation implications for this endangered population. Anim Behav 77:963-971

Pistorius PA, Taylor FE, Louw C, Hanise B and others (2002) Distribution, movement, and estimated population size of killer whales at Marion Island, December 2000. S Afr J Wildl Res 32:86-92

Poncelet E, Barbraud C, Guinet C (2010) Population dynamics of killer whales (Orcinus orca) in the Crozet Archipelago, southern Indian Ocean: a mark-recapture study from 1977 to 2002. J Cetacean Res Manage 11:41-48

Prince Edward Islands Management Plan Working Group (1996) Prince Edward Islands Management Plan. Department of Environmental Affairs and Tourism, Pretoria, South Africa

Reisinger RR, de Bruyn PJN, Bester MN (2011) Prey and seasonal abundance of killer whales at subantarctic Marion Island. Afr J Mar Sci doi:10.2989/1814232X.2011.572356

Schwarz CJ, Arnason AN (1996) A general methodology for the analysis of capture-recapture experiments in open populations. Biometrics 52:860-873

Editorial responsibility: Hans Heinrich Janssen, Oldendorf/Luhe, Germany
Schwarz CJ, Arnason AN (2009) Jolly-Seber models in MARK. Cooch E, White G (eds) Program MARK: a gentle introduction, 8th edn. Available at www.phidot.org/software/mark/ docs/book

Springer AM, Estes JA, van Vliet GB, Williams TM and others (2003) Sequential megafaunal collapse in the North Pacific Ocean: an ongoing legacy of industrial whaling? Proc Natl Acad Sci USA 100:12223-12228

Tixier P, Gasco N, Duhamel G, Viviant M, Authier M, Guinet C (2010) Interactions of Patagonian toothfish fisheries with killer and sperm whales in the Crozet Islands Exclusive Economic Zone: an assessment of depredation levels and insights on possible mitigation strategies. CCAMLR Sci 17: 179-195

Tosh CA, de Bruyn PJN, Bester MN (2008) Preliminary analysis of the social structure of killer whales, Orcinus orca, at subantarctic Marion Island. Mar Mamm Sci 24:929-940

Weimerskirch H, Inchausti P, Guinet C, Barbraud C (2003) Trends in bird and seal populations as indicators of a system shift in the Southern Ocean. Antarct Sci 15:249-256

White GC, Burnham KP (1999) Program MARK: survival estimation from populations of marked animals. Bird Study (Suppl) 46:120-138

Williams R, Thomas L (2009) Cost-effective abundance estimation of rare animals: testing performance of small-boat surveys for killer whales in British Columbia. Biol Conserv 142:1542-1547

Williams TM, Estes JA, Doak DF, Springer AM (2004) Killer appetites: assessing the role of predators in ecological communities. Ecology 85:3373-3384

Wilson B, Hammond PS, Thompson PM (1999) Estimating size and assessing trends in a coastal bottlenose dolphin population. Ecol Appl 9:288-300

Submitted: May 12, 2010; Accepted: March 21, 2011 Proofs received from author(s): April 27, 2011 